\title{
Determinants of Summiting Success and Acute Mountain Sickness on Mt Kilimanjaro (5895 m)
}

\author{
Andrew J. Davies, MBChB, BSc (Hons); Nicholas S. Kalson, BSc (Hons); Suzy Stokes, MBChB (Hons); \\ Mark D. Earl, MRes; Adam G. Whitehead, BSc (Hons); Hannah Frost, BSc (Hons); Ian Tyrell-Marsh, \\ MBChB (Hons); Jon Naylor, MBChB, MRCP
}

From the Manchester Altitude Research Society, University of Manchester Medical School, Manchester, UK (Dr Davies, Mr Kalson, Dr Stokes, Mr Earl, Mr Whitehead, Ms Frost, and Dr Tyrell-Marsh); the Salford Royal NHS Foundation Trust, Salford, UK (Dr Davies); University Hospital of North Staffordshire, Staffordshire, UK (Dr Stokes); North Manchester General Hospital, Delaunays Rd, Crumpsall, Manchester, UK (Dr TyrellMarsh); and the Ministry of Defence Hospital Unit, Peterborough District Hospital, Peterborough, UK (Dr Naylor).

\begin{abstract}
Objective.-To determine the incidence of acute mountain sickness (AMS), the frequency of summiting success, and the factors that affect these in trekkers on Kilimanjaro, one of the world's most summitted high-altitude peaks.

Methods.-The study group comprised 312 trekkers attempting Mt Kilimanjaro summit by the Marango Route. Trekkers ascended over 4 or 5 days along a fixed ascent profile, stopping at 3 huts on ascent $(2700 \mathrm{~m}, 3700 \mathrm{~m}$, and $4700 \mathrm{~m})$ before attempting the summit. Researchers were stationed at each hut for 16 days. Each night we measured heart rate, respiratory rate, blood pressure, oxygen saturation, and Lake Louise Score. We recorded the highest altitude that trekkers reached on the mountain.

Results.-Of 181 complete sets of data, $111(61 \%)$ trekkers reached the summit, and $139(77 \%)$ developed AMS. Physiological results were not related to summit success. The incidence of AMS and summiting success were similar in those on the 4- or 5-day route. Trekkers on the 5-day route who used acetazolamide were less likely to develop AMS and more likely to summit than were those not taking acetazolamide $(P=<.05)$; this difference was not present with trekkers on the 4-day route.

Conclusions.-The risk of developing AMS is high on Mt Kilimanjaro. Although taking an extra day to acclimatize with the use of acetazolamide did provide some protection against AMS, ideally trekkers need a more gradual route profile for climbing this mountain.
\end{abstract}

Key words: altitude, acclimatization, acetazolamide

\section{Introduction}

Mt Kilimanjaro, the highest mountain in Africa (5895 m), is a popular tourist destination and perhaps the most climbed high-altitude peak in the world, with at least 30000 trekkers attempting it each year. ${ }^{1,2}$ All visitors to high altitude risk developing acute mountain sickness (AMS). Mt Kilimanjaro is regarded as the highest freestanding mountain in the world, rising directly from a lowland plateau with no foothills, and unlike trekking routes in the Himalayas and Andes, it is easily accessed

Andrew J. Davies and Nicholas S. Kalson contributed equally to this manuscript.

Corresponding author: Andrew Davies, MBChB, BSc, 33 St Wilfrids St, Hulme, Manchester, M15 5XE, UK (e-mail: andrewjohndavies@ doctors.org.uk). from an international airport located less than $40 \mathrm{~km}$ away. Consequently, climbers face poor acclimatization and high rates of AMS. This is compounded by an ascent route that involves no technical climbing and by the mountain's fame as one of the continental "seven summits" (the highest mountain in one of the 7 continents); thus, many professional trekking companies market Mt Kilimanjaro as "a challenge of a lifetime," and, indeed, for many people it is. As a result of these factors it is often ascended by relatively inexperienced trekkers and is frequently used to raise money for charities.

While several routes exist up the mountain, the most popular is the Marango Route, colloquially known as the "Coca-Cola Route"; most trekkers take 4 or 5 days to ascend from the Tanzanian lowlands $(<1500 \mathrm{~m})$ to the summit. This contravenes established advice that a slow 
ascent is favorable, and once above $3000 \mathrm{~m}$ an individual should not ascend more than 300 to $600 \mathrm{~m}$ in a 24-hour period, with occasional rest days in addition., ${ }^{3,4}$ Other routes take 6 to 8 days to ascend the mountain, but a combination of factors makes them less popular. Trekkers must stay in tents rather than the huts that exist on the Marango Route, which carries a perceived relative lack of comfort as well as the extra costs involved in carrying this equipment. The current cost of National Park fees and accommodation are US $\$ 110$ per day, making longer routes significantly more expensive. Finally, many trekkers incorporate the ascent of this mountain into a busy holiday schedule that includes visiting such regional attractions as the safari and the Indian Ocean beaches.

All visitors to high altitude are at risk of illness, notably AMS, high-altitude cerebral edema, and highaltitude pulmonary edema, and there is an abundance of literature $^{5-7}$ on AMS and altitude-related pathology. However, there is little work specifically on $\mathrm{Mt}$ Kilimanjaro with its unique ascent profile. ${ }^{8}$

Hypoxemia is thought to be central to the development of AMS (reviewed in Hackett and Roach ${ }^{5}$ and Basnyat and Murdoch $^{6}$ ), and low arterial oxygen saturation is associated with AMS, both on acute ${ }^{9}$ and long-tem exposure to hypoxia. ${ }^{10}$ Trekking companies on Mt Kilimanjaro are now making basic physiological measurements, such as arterial oxygen saturation $\left(\mathrm{SaO}_{2}\right)$, to educate their clients.

The efficacy of acetazolamide for pharmacologic prophylaxis of AMS is well established. ${ }^{11}$ Mechanisms underlying its benefit are complex and incompletely understood, but they include improved arterial oxygen saturation (by increasing minute ventilation) and increased diuresis. $^{12,13}$

We hypothesized that the incidence and intensity of AMS would be decreased and summit success increased by an extra day of acclimatization and also by use of acetazolamide. We hypothesized that trekkers with lower $\mathrm{SaO}_{2}$ were less likely to reach the summit.

\section{Methods}

The study was approved by the Tanzanian National Institute for Medical Research, the Tanzanian Commission for Science and Technology (2005-261-NA-200562), and the Tanzanian National Parks Authority. Written informed consent was obtained from all volunteers.

\section{PARTICIPANTS}

Participants in the study were tourist trekkers attempting to reach the summit of Mt Kilimanjaro (5895 m) in Tanzania between July 31, 2005, and August 15, 2005. Trekkers exposed to altitudes of $>3000 \mathrm{~m}$ in the previous 2 weeks and those whose command of English was not sufficient to give consent were excluded from the study.

All participants ascended by the Marango Route, upon which trekkers stayed at fixed huts on their ascent: all stayed for 1 night each at $2700 \mathrm{~m}, 3700 \mathrm{~m}$, and $4700 \mathrm{~m}$, and some had an extra (second) overnight stop at $3700 \mathrm{~m}$. All trekkers then attempted the summit $(5895 \mathrm{~m})$ and stopped at $3700 \mathrm{~m}$ on descent. Researchers were stationed on the mountain at each of the 3 huts simultaneously.

All trekkers attempting the summit were recruited at the first hut on their ascent $(2700 \mathrm{~m})$. Written informed consent was obtained, and trekkers were asked to report to a researcher each evening while on the mountain, during both ascent and descent, when the incidence of AMS and its intensity was determined using the Lake Louise Score (LLS). ${ }^{14}$ As used by others, a score of $\geq 4$, including headache, was used to define the presence of AMS. ${ }^{15}$ Acute mountain sickness on the summit day was determined retrospectively at $4700 \mathrm{~m}$ on descent.

Body mass index was determined as weight $(\mathrm{kg}) /$ height $^{2}$ (m); $\mathrm{SaO}_{2}$ was determined using a pulse oximeter (Nellcor N-20PA, Tyco Healthcare, Swindon, UK). Blood pressure was measured using a portable monitor (M10-IT model, Omron-Healthcare, Henfield, UK). Mean arterial pressure was calculated as diastolic pressure $+1 / 3 \times$ (systolic pressure - diastolic pressure). Heart rate (beats/min) and respiratory rate (breaths/min) were also measured. The average of 3 readings was taken for physiological variables, after a minimum of 30 minutes at rest.

\section{DATA ANALYSIS}

Results were analysed using SPSS version 14. MannWhitney $U$ test with the Bonferroni correction was used to determine differences in physiological variables and mean AMS scores. A $\chi^{2}$ test was used to determine differences in summiting success and AMS incidence.

\section{Results}

During the study 350 trekkers were approached, of which 312 agreed to participate. Thirty-one trekkers were excluded from the study because of recent altitude exposure or because they had type 1 diabetes mellitus (the latter group used a longer ascent profile ${ }^{16}$ ). One hundred trekkers (66 male) of the remaining 281 were lost to follow-up during the study. After these losses, 181 complete sets of data from trekkers who attempted the summit were available for analysis. These were subdivided into different groups: those who spent 4 days ascending the mountain (4-day ascent profile) and those who spent an extra night at $3700 \mathrm{~m}$ to acclimatize (5-day ascent profile); and those who took acetazolamide during 


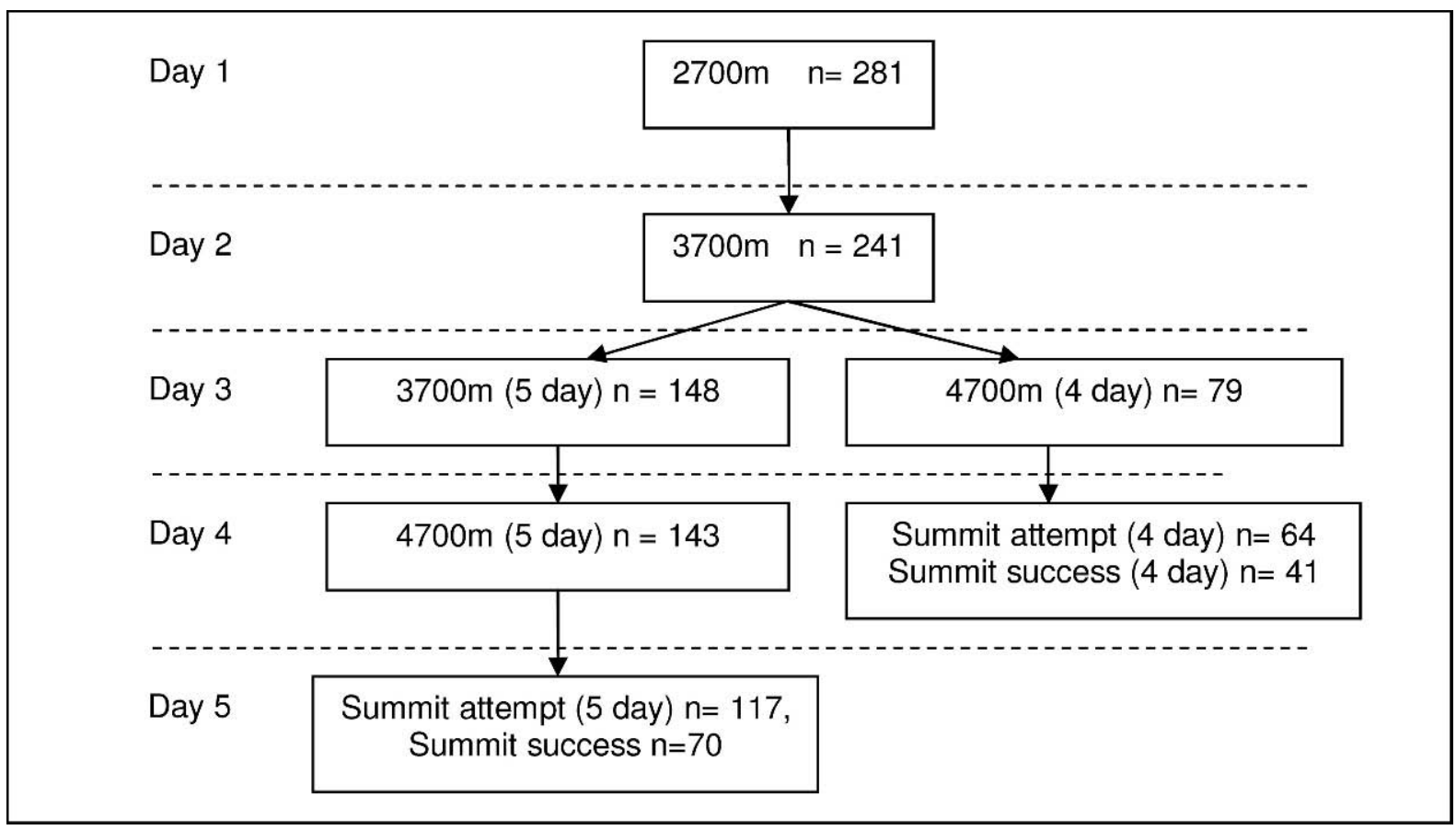

Figure 1. Schematic of subject progression up Mt Kilimanjaro. The 2 ascent profiles (4-day ascent and 5-day ascent) were not equally used, and loss to follow-up occurred at each stage. Of the 281 trekkers recruited, 241 were followed up at $3700 \mathrm{~m}$, of which 148 spent a second night at this altitude (5 days). One hundred and forty-three of the 5-day cohort were followed up at $4700 \mathrm{~m}$ and 117 on summit day. On the 4-day route 79 were followed up at $4700 \mathrm{~m}$, of which 64 were seen on the summit day.

their ascent and those who did not. Of 181 trekkers who completed the study, 54 were taking prophylactic acetazolamide in doses ranging from 250 to $750 \mathrm{mg}$ daily. Physical characteristics (height $173 \pm 10 \mathrm{~cm}$, weight 70.1 $\pm 30.1 \mathrm{~kg}$, age $32.3 \pm 12.2$ years) were not different between those lost from follow-up and those completing the study, between those on the 2 ascent routes, or between those who were either taking or not taking acetazolamide (data not shown). Figure 1 shows the rate at which trekkers were lost from the study and the division between the 5-day group and the 4-day group.

\section{TREKKERS NOT TAKING ACETAZOLAMIDE}

\section{Ascent route}

An extra day of acclimatization made no difference to summit success $(27 / 41$ on 4 -day route [66\%] vs 43/86 [50\%] on the 5-day route; $P=.09$; Table 1 ).

\section{Physical characteristics and physiology}

No differences in age or body mass index were found between successful and unsuccessful trekkers. After adjusting for multiple comparisons (Bonferroni), no difference in physiology was found between successful and unsuccessful trekkers on either the 4- or 5-day ascent profile routes (Table 2).

\section{Acute mountain sickness}

Acute mountain sickness intensity (LLS score) rose with increasing altitude (Figure 2). Scores were not different between trekkers on 4-day and 5-day ascent profiles. There was variation in AMS intensity (eg, at $4700 \mathrm{~m}$ scores ranged from 0 to 11 and on the summit day from 0 to 21).

Table 1. Summit success in trekkers attempting the summit of Mt Kilimanjaro

\begin{tabular}{|c|c|c|c|c|c|c|}
\hline & \multicolumn{6}{|c|}{ Summit success } \\
\hline & \multicolumn{3}{|c|}{$4-d$} & \multicolumn{3}{|c|}{$5-d$} \\
\hline & Yes & No & Success, \% & Yes & No & Success, \% \\
\hline $\mathrm{AZ}$ & 14 & 9 & 61 & $27 *$ & 4 & 87 \\
\hline No AZ & 27 & 14 & 66 & $43 *$ & 43 & 50 \\
\hline \multirow[t]{3}{*}{ Total } & 41 & 23 & & 70 & 47 & \\
\hline & \multirow{2}{*}{\multicolumn{2}{|c|}{64}} & & \multicolumn{2}{|c|}{117} & \\
\hline & & & 18 & & & \\
\hline
\end{tabular}

*Indicates a significant difference in summit success rate in trekkers taking acetazolamide (AZ) compared with those not taking acetazolamide on the 5-day route. 
Table 2. Differences in physiology at $4700 \mathrm{~m}$ on ascent between successful $(n=70)$ and unsuccessful $(n=57)$ trekkers. $P$ values are comparison between successful and unsuccessful trekkers in the 2 groups (those taking or not taking acetazolamide)* $\dagger$ t

\begin{tabular}{|c|c|c|c|c|c|c|c|c|c|c|c|c|}
\hline & \multicolumn{6}{|c|}{ 4-d Ascent profile } & \multicolumn{6}{|c|}{ 5-d Ascent profile } \\
\hline & \multicolumn{3}{|c|}{$A Z$} & \multicolumn{3}{|c|}{ No $A Z$} & \multicolumn{3}{|c|}{$A Z$} & \multicolumn{3}{|c|}{ No $A Z$} \\
\hline & Success & Failed & $\mathrm{P}$ & Success & Failed & $\mathrm{P}$ & Success & Failed & $\mathrm{P}$ & Success & Failed & $\mathrm{P}$ \\
\hline Age & 24.54 & 31.63 & .17 & 39.57 & 35.12 & .29 & 31.54 & 32.50 & .90 & 36.05 & 34.84 & .39 \\
\hline BMI & 22.32 & 23.06 & .56 & 22.75 & 23.67 & .27 & 23.94 & 23.34 & .70 & 23.18 & 22.90 & .70 \\
\hline $\mathrm{SaO}_{2}$ & $86.77 *$ & $81.5^{*}$ & .01 & $79.48^{*}$ & $76.4^{*}$ & .24 & $84.44 *$ & $85.5^{*}$ & .65 & $79.21 *$ & $82.59 *$ & .18 \\
\hline $\mathrm{HR}$ & 95.08 & 96.25 & .85 & 95.70 & 95.67 & .96 & 98.26 & 90.25 & .26 & 110.13 & 94.73 & .94 \\
\hline RR & 15.83 & 18.88 & .16 & 20.20 & 16.92 & .03 & 17.67 & 20.33 & .07 & 18.11 & 17.83 & .65 \\
\hline MAP & 95.64 & 95.06 & .88 & 101.28 & 94.53 & .02 & 100.70 & 94.00 & .20 & 100.03 & 86.03 & .06 \\
\hline
\end{tabular}

*Significant difference in $\mathrm{SaO}_{2}$ between trekkers taking acetazolamide and those not taking acetazolamide on both 4-day and 5-day routes $(P=$ $.002)$.

$\uparrow \mathrm{AZ}$ indicates acetazolamide; Age in years; $\mathrm{BMI}$, body mass index; $\mathrm{SaO}_{2}$, arterial oxygen saturation \%; HR, heart rate in beats per minute; $\mathrm{RR}$, respiratory rate in breaths per minute; and MAP, mean arterial pressure in $\mathrm{mm} \mathrm{Hg}$.

$\$$ No differences significant at $P<.008$ (Bonferroni adjusted).

The presence of AMS (LLS $\geq 4$ ) had no influence on summit success in trekkers on both the 4-day and 5-day ascent profiles. Acute mountain sickness incidence was significantly higher on the summit day in those on the 4-day ascent profile compared with trekkers on the 5-day ascent profile $(37 / 41[90 \%]$ vs $61 / 86[71 \%] ; P=.02$; Table 3$)$.

\section{Trekkers taking acetazolamide}

Summit success and ascent route

In trekkers taking acetazolamide, the extra day of acclimatization improved summit success from 14/23 (61\%) to $27 / 31(87 \%, P=.03)$.

\section{Mean Lake Louise Score on the Marangu Route on Mt Kilimanjaro}

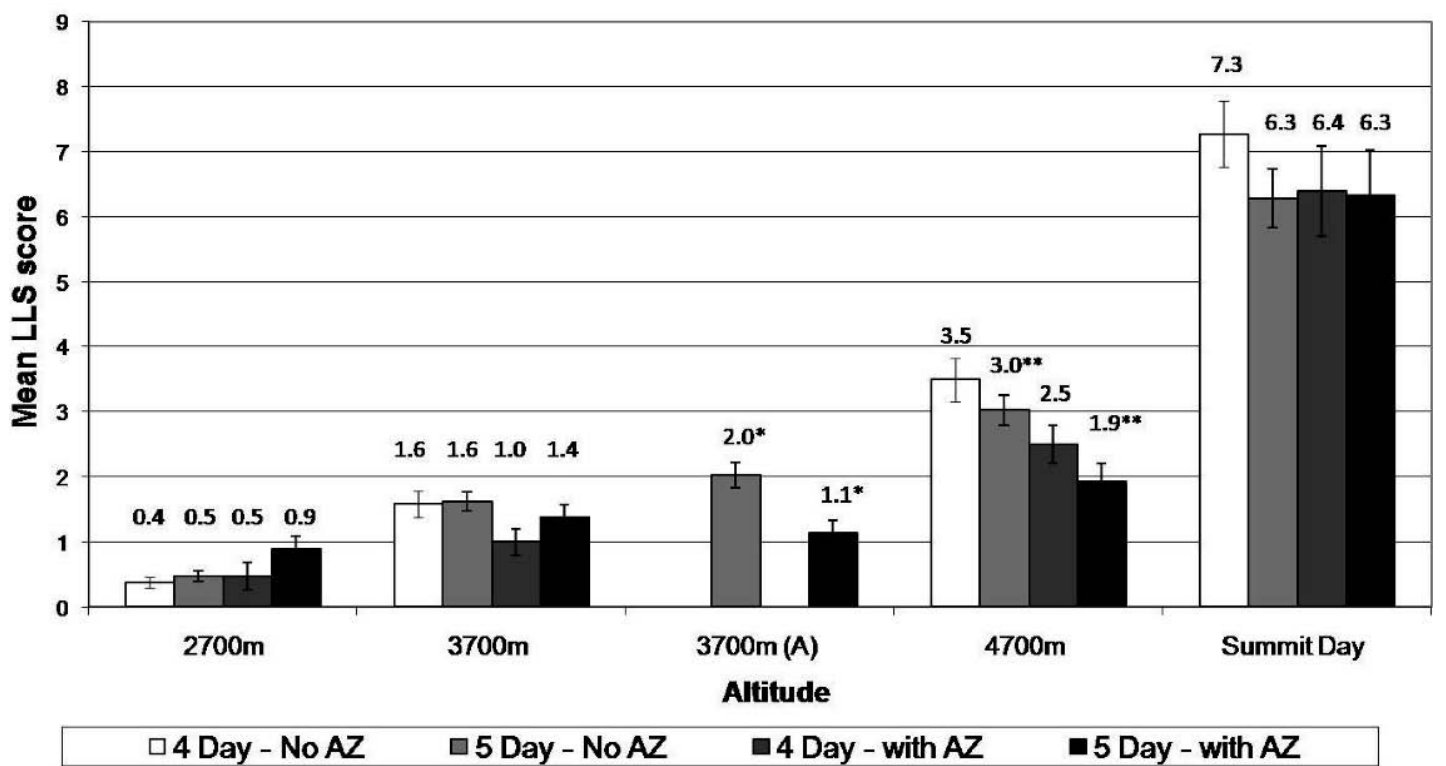

Figure 2. Mean acute mountain sickness scores varying with altitude on Mt Kilimanjaro. Significant differences between 5-day ascent profile climbers taking acetazolamide (AZ) and those not taking acetazolamide at $3700 \mathrm{~m}(*)$ and $4700 \mathrm{~m}(* *)$ are shown on the graph $(P=.02$ and .04 , respectively). 


\section{Physical characteristics and physiology}

No differences in physical (age, body mass index) or physiological (heart rate, respiratory rate, mean arterial pressure, $\mathrm{SaO}_{2}$ ) variables were seen between successful and unsuccessful trekkers (Table 2). Higher $\mathrm{SaO}_{2}$ was seen in comparing trekkers taking acetazolamide to those not taking acetazolamide (Table 2).

\section{Acute mountain sickness}

Significantly lower LLS scores were seen in trekkers taking acetazolamide compared with trekkers not taking acetazolamide on the 5-day ascent profile at both $3700 \mathrm{~m} \mathrm{(1.1} \mathrm{vs}$ $2.0 ; P=.02)$ and $4700 \mathrm{~m}(1.9$ vs $3.0 ; P=.04$; Figure 2$)$.

The incidence of AMS was greater in those not taking acetazolamide at $4700 \mathrm{~m}$ than in those taking acetazolamide on the 5-day ascent profile (42/105 [40\%] vs 8/38 [21.1\%]; $P=.04$; Table 3 ). There was no difference in trekkers on the 4-day ascent profile ( $9 / 28$ [32\%] vs $24 / 51$ [47\%]; $P=.10)$. No significant differences at any other altitude were seen.

\section{COMORBIDITIES}

The cohort included several trekkers with comorbidities. Six trekkers had treated hypertension, of which $3(50 \%)$ made it to the summit (none taking acetazolamide, all on 4-day ascent route). Ten trekkers followed up on summit day had asthma, 4 on the 4-day ascent route and 6 on the 5-day route, including 4 trekkers on acetazolamide. Five $(50 \%)$ achieved the summit ( 3 on the 4-day route and 2 on the 5-day route). ${ }^{17}$ Two out of 4 asthmatic trekkers taking acetazolamide achieved the summit (1 on the 4-day route and 1 on the 5-day route).

\section{ENTIRE COHORT ANALYSIS}

The success rate for the entire cohort achieving the summit was $111 / 181(61.3 \%)$. For those who did not succeed in reaching the summit, 29/181 (16.0\%) stopped at Gilmans' Point $(5600 \mathrm{~m})$ on the summit crater rim but 1.5 hours walk to the summit, $26 / 181(14.4 \%)$ descended at various points between setting off from $4700 \mathrm{~m}$ and $5600 \mathrm{~m}$ (Gilmans' Point), while 15/181 (8.3\%) failed to leave the final hut at $4700 \mathrm{~m}$. The overall incidence of AMS during the summit attempt day was 139/181 (77\%).

\section{Discussion}

The main findings of the study are as follows:

1. There is a high incidence of AMS on Mt Kilimanjaro;

2. Many trekkers will be unsuccessful in reaching the summit; and

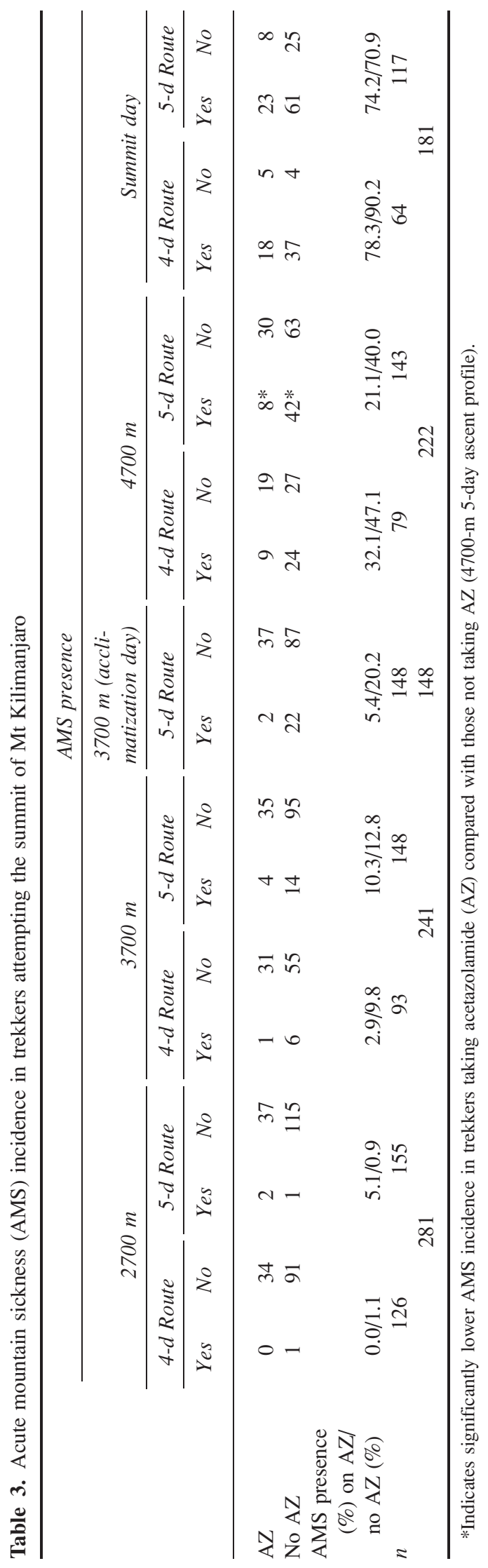


3. Acetazolamide improves summit success and reduces the incidence and intensity of AMS, but only for those on a slower ascent profile.

The incidence of AMS for all trekkers was $77 \%$, which is among the highest incidence rates of any trekking location in the world. In addition, only $61 \%$ of trekkers reached the summit $(5895 \mathrm{~m})$. This is comparable to an observational study ${ }^{18}$ that found an AMS incidence of 75\% among Finnish trekkers ascending Mt Kilimanjaro. In the same study only $53 \%$ of trekkers reached $5600 \mathrm{~m}$ (Gilmans' Point). Other studies found an incidence of $60 \%$ on Mt Damavand (5671 m, Iran) ${ }^{19} 68 \%$ in Gosaikund Lake (4300 m, Nepal), ${ }^{20}$ and $92 \%$ at $5500 \mathrm{~m}$ in Peru. ${ }^{21}$

Acute mountain sickness, high-altitude pulmonary edema, and high-altitude cerebral edema are potentially fatal diseases that are avoidable with appropriate preparation. Kilimanjaro Christian Medical Centre (the nearest hospital to the mountain) reported 25 tourist deaths on Kilimanjaro between January 1996 and October 2003, 14 of which were attributable to highaltitude illnesses, ${ }^{2}$ although we saw no cases of highaltitude pulmonary edema or high-altitude cerebral edema among our study population. No figures were available for porters.

In those not taking acetazolamide, the choice of ascent profile did not affect summit success. The 5-day cohort, which took an extra day for acclimatization, actually had a lower success rate than did those trekkers on the 4-day route. It is possible that they were a more cautious group who were willing to turn around on summit day with early signs of AMS.

An acclimatization day at $3700 \mathrm{~m}$ was associated with lower AMS incidence on summit day, although this incidence rate was still high $(72 \%$ vs $86 \%$, trekkers with and without acetazolamide, respectively). The lack of flexibility in route choice coupled with branding of the Marango Route as "easy" is dangerous and disappointing for many trekkers. There are several routes up Mt Kilimanjaro that take longer than 5 days, with a gentler ascent profile and better acclimatization. Anecdotal information from trekking companies indicated success rates of $>95 \%$ on the Western Breach Route, on which trekkers typically ascend over 6 days or more (oral communication Kilitreks Tour operator, 2005).

Overall, the lowest incidence of AMS and the highest rate of summit success were in trekkers on the 5-day ascent profile who were taking acetazolamide. Acetazolamide is effective in reducing the symptoms of AMS, and it is a useful adjunct for high-altitude visits. ${ }^{22,23} \mathrm{We}$ did not record trekkers' dosages or compliance, although it was clear that use of this drug had a measurable benefit in terms of both AMS incidence and chance of summiting. However, even in those taking acetazolamide, levels of AMS were still high, and side effects can be unpleasant (including diuresis and paresthesia ${ }^{4}$ ). Its use is a matter of individual choice, but acetazolamide is not a substitute for good acclimatization. Our research group of 7 spent 16 days on the mountain before achieving $100 \%$ summit success with $0 \%$ AMS incidence.

One strength of our study was the Marango Route, selected because the rapid ascent produces a high incidence of AMS and allows researchers to follow trekkers at regular intervals. Additionally, the population has little previous acclimatization experience; only $10 \%$ of trekkers had visited high altitude in the previous 2 weeks, and the whole group is representative of a general trekking population (rather than comprising elite mountaineers). However, our study does have weaknesses, mainly relating to inevitable logistic problems of such fieldwork. One hundred trekkers were lost to follow-up during the study. Some of these may have chosen to descend or withdraw from the study as a result of AMS, which might have caused an underestimate of the presence of AMS and an overestimate of summit success.

Our study highlights areas for future work. There is still uncertainty over the optimal acetazolamide dosing regime. We did not find differences in physiological variables, easily measured on the mountain, between those who succeeded and those who failed to summit. Measurements are being taken by some climbing companies to provide information for their clients, but further investigation is needed if recommendations on continuation of the trek are to be made based on these measurements. We were unable to examine the porters who work on this mountain. The International Porter Protection Group ${ }^{24}$ can provide more information on the problems they encounter.

The vast majority of trekkers had a thoroughly enjoyable experience climbing Mt Kilimanjaro, and most healthy individuals should be able to reach the summit. People should take this ascent seriously, either by taking one of the longer routes up the mountain or by acclimatizing on nearby peaks such as Mt Meru (4566 m) or Mt Kenya (5199 m).

\section{Acknowledgments}

The authors would like to thank Tanzania National Parks (TANAPA) and Kilimanjaro National Park for kindly permitting us to use Mt Kilimanjaro for research purposes. We would also like to thank Dr Kyle Pattinson, University of Oxford, for his invaluable support and advice in the writing of this article. 


\section{References}

1. Fitzpatrick M, Fletcher M, Wenk D, eds. Trekking in East Africa. 3rd ed. Melbourne, Australia: Lonely Planet Publications Pty Ltd; 2003.

2. Hauser M, Mueller A, Swai B, Moshi E, Ole Nguyaine S. Deaths due to high altitude illness among tourists climbing Mt Kilimanjaro. Proceedings of the 2004 South African Travel Medicine Society, Cape Town, South Africa, Feb 911, 2004. Available at: http://www.sastm.org.za/articles/ AECTM-Abstracts.pdf. Accessed May 5, 2008.

3. Ward MP, Milledge JS, West JB. High Altitude Medicine and Physiology. 3rd ed. London, UK: Arnold Publishers Ltd; 2000.

4. Pollard AJ, Murdoch DR. The High Altitude Medicine Handbook. 3rd ed. Abingdon, UK: Radcliffe Medical Press Ltd; 2003.

5. Hackett PH, Roach RC. High-altitude illness. N Engl J Med. 2001;345:107-114.

6. Basnyat B, Murdoch DR. High-altitude illness. Lancet. 2003;361:1967-1974.

7. Schoene RB. Unraveling the mechanism of high altitude pulmonary edema. High Alt Med Biol. 2004;5:125-135.

8. Expedition Advisory Centre of the Royal Geographical Society. Guidance for those trekking on Mt Kilimanjaro. Available at: http://www.rgs.org/NR/rdonlyres/AF725A7E276D-4007-94A5-66AD67C3D83B/0/kilimanjaro.pdf. Accessed March 9, 2008.

9. Burtscher M, Szubski C, Faulhaber M. Prediction of the susceptibility to AMS in simulated altitude. Sleep Breath. 2008; 12:103-108.

10. Roach RC, Greene ER, Schoene RB, Hackett PH. Arterial oxygen saturation for prediction of acute mountain sickness. Aviat Space Environ Med. 1998;69:1182-1185.

11. Leaf DE, Goldfarb DS. Mechanisms of action of acetazolamide in the prophylaxis and treatment of acute mountain sickness. J Appl Physiol. 2007;102:1313-1322.

12. Ried LD, Carter KA, Ellsworth A. Acetazolamide or dexamethasone for prevention of acute mountain sickness: a meta-analysis. J Wilderness Med. 1994;5:34-48.

13. Swenson ER, Duncan TB, Goldberg SV, Ramirez G, Ahmad S, Schoene RB. Diuretic effect of acute hypoxia in humans: relationship to hypoxic ventilatory responsiveness and renal hormones. J Appl Physiol. 1995;78:377-383.

14. Roach R, Bartsch P, Hackett PH, Oelz O. The Lake Louise AMS Scoring Consensus Committee. The Lake Louise acute mountain sickness scoring system. In: Sutton JR,
Coates G, Hutton CS, eds. Hypoxia and Molecular Medicine: Proceedings of the 8th International Hypoxia Symposium. February 9-13, 1993; Lake Louise, Canada. Burlington, VT: Queen City Printers; 1993.

15. Maggiorini M, Muller A, Hofstetter D, Bartsch P, Oelz O. Assessment of acute mountain sickness by different score protocols in the Swiss Alps. Aviat Space Environ Med. 1998;69:1186-1192.

16. Kalson NS, Davies AJ, Stokes S, et al. Climbers with diabetes do well on Mount Kilimanjaro. Diabet Med. 2007; 24:1496

17. Stokes S, Kalson N, Earl M, et al. Bronchial asthma on Mount Kilimanjaro is not a disadvantage. Thorax. 2008;63: 936-937.

18. Karinen H, Peltonen J, Tikkanen H. Prevalence of acute mountain sickness among Finnish trekkers on Mount Kilimanjaro, Tanzania: an observational study. High Alt Med Biol. 2008;9:301-306.

19. Ziaee V, Yunesian M, Ahmadinejad Z, et al. Acute mountain sickness in Iranian trekkers around Mount Damavand $(5671 \mathrm{~m})$ in Iran. Wilderness Environ Med. 2003;14:214-219.

20. Basnyat B, Subedi D, Sleggs J, et al. Disoriented and ataxic pilgrims: an epidemiological study of acute mountain sickness and high-altitude cerebral edema at a sacred lake at $4300 \mathrm{~m}$ in the Nepal Himalayas. Wilderness Environ Med. 2000;11:89-93.

21. Imray CH, Kennedy $\mathrm{CH}$, Pattison K, Brearey S, Wright A; Birmingham Medical Research Expeditionary Society. Self-assessment of acute mountain sickness in adolescents: a pilot study. Wilderness Environ Med. 2004;15:202206.

22. Basnyat B, Gertsch JH, Johnson EW, Castro-Marin F, Inoue $\mathrm{Y}$, Yeh $\mathrm{C}$. Efficacy of low-dose acetazolamide (125 mg BID) for the prophylaxis of acute mountain sickness: a prospective, double-blind, randomized, placebo-controlled trial. High Alt Med Biol. 2003;4:45-52.

23. Gertsch JH, Basnyat B, Johnson EW, Onopa J, Holck PS. Prevention of High Altitude Illness Trial Research Group. Randomised, double blind, placebo controlled comparison of gingko biloba and acetazolamide for prevention of acute mountain sickness among Himalayan trekkers: the prevention of high altitude illness trial (PHAIT). BMJ. 2004;328: 797.

24. International Porter Protection Group. Available at: http:// www.ippg.net. Accessed July 20, 2008. 